Available online at GSC Online Press Directory

GSC Advanced Research and Reviews e-ISSN: 2582-4597, CODEN (USA): GARRC2

Journal homepage: https://www.gsconlinepress.com/journals/gscarr

(RESEARCH ARTICLE)

\title{
Application of foaming capacity as response value in optimization of biosurfactant production
}

\author{
Lekiah Pedro Peekate* and Chukwuemeka John Ugboma \\ Department of Microbiology, Faculty of Science, Rivers State University, P.M.B. 5080 Port Harcourt, Nigeria.
}

Publication history: Received on 06 August 2020; revised on 13 August 2020; accepted on 15 August 2020

Article DOI: https://doi.org/10.30574/gscarr.2020.4.2.0064

\begin{abstract}
Equipment for determination of surface tension (ST) which is the response value often used during biosurfactant optimization are not readily available in many laboratories. Foaming capacity (FC) was thus investigated as response value during biosurfactant optimization. Thirteen variations of glycerol-mineral salts medium were used to culture Pseudomonas sp. for biosurfactant production and optimization. Variations in the medium were based on $\mathrm{pH}$, carbonnitrogen (C-N) and carbon-phosphorus (C-P) ratio. Inoculated media were incubated at ambient temperature with orbital shaking at $150 \mathrm{rpm}$ for four days. FC of the media were then determined and fitted using a polynomial model so as to obtain a prediction profile. The prediction profile was used to determine the combination of C-N ratio, C-P ratio, and $\mathrm{pH}$ that will lead to the highest FC. This combination was used in another experimental run for biosurfactant production, and at the end the culture was screened for biosurfactant activity. The results obtained showed that foaming was achieved in selected experimental runs, and the model for the prediction profile was worked out to be $\mathrm{Y}=-513.03$ $+103.3804 X_{1}+2.1211 X_{2}+16.2848 X_{3}-0.1108 X_{1} X_{2}-0.3656 X_{1} X_{3}-0.0339 X_{2} X_{3}-6.1730 X_{1}^{2}-0.0099 X_{2}^{2}-0.4432 X_{3}^{2}$. From the prediction profiles it was seen that the highest FC $(32.04 \%)$ was achievable at combination of $\mathrm{pH} 7.0$, C-N 40, and C-P 13. Biosurfactant activity of the culture with optimized combination showed that ST reduced from 56.43 to $35.28 \mathrm{mN}^{-1}{ }^{-1}$. It is concluded that FC can be used in place of ST during biosurfactant optimization procedures.
\end{abstract}

Keywords: Foaming capacity; Surface tension; Biosurfactant; Optimization; Response surface methodology.

\section{Introduction}

Biosurfactants are surface active compounds synthesized by certain genera of bacteria and selected yeasts [1]. Industrial scale production of biosurfactant is economically challenging [2]. Researchers thus carry out product optimization so as to proffer procedures and processes that will minimize waste of substrates while ensuring maximum product yield. Optimization of Biosurfactant production involves coming up with a set of conditions that will lead to maximum or optimum yield of biosurfactant during production. This has been achieved with the use of Response surface methodology (RSM) with three to five variable mathematical designs/models such as the Box-Behnken design [3, 4]. In RSM all chosen variables are optimized simultaneously, thus eliminating the limitations associated with a single factor optimization process.

Biosurfactants are capable of lowering surface tension [5], and this property is most often used in screening for biosurfactant production. Surface tension is also the response value more often used when RSM is applied in biosurfactant optimization $[4,6,7]$. Surface tension determination during assessment for biosurfactant production is achieved using the Du-Nouy-Ring method and the capillary rise method [8, 9, 10]. In the Du-Nouy-ring method, an instrument called a tensiometer is used in measuring the surface tension [10]. In the capillary rise method a capillary tube is used in measuring the rise in height which is used alongside other parameters in calculating surface tension [11].

\footnotetext{
* Corresponding author: Lekiah Pedro Peekate lekia.peekate@ust.edu.ng

Department of Microbiology, Faculty of Science, Rivers State University, P.M.B. 5080 Port Harcourt, Nigeria.
} 
Tensiometers and calibrated capillary tubes are equipment not readily available in many Microbiology laboratories in developing countries. There are however other methods that rely on simple apparatus that are readily available in any Microbiology laboratory that can be used in detecting and estimating biosurfactant production. They include the oil spread assay, emulsification capacity, and foaming capacity [12, 13, 14]. The values obtained from these methods are quantitative, and can be use as response values when applying RSM in biosurfactant optimization. The aim of this research work is thus to determine the effectiveness of using foaming capacity as a response value in the optimization of biosurfactant production.

\section{Material and methods}

\subsection{Sourcing for a biosurfactant producing bacterium}

Bacteria that produce biosurfactants include Bacillus spp., Rhodococcus spp., and Pseudomonas spp. [15, 16, 17]. Pseudomonas sp. was chosen and isolated for use as the biosurfactant producing bacterium.

Water samples were collected from fish ponds in the African Regional Aquaculture Centre (ARAC), Port Harcourt, Nigeria. The samples were collected with the aid of disinfected water bottles of about 500 ml capacities. Pseudomonas species were isolated from the water samples using nutrient agar supplemented with $60 \mu \mathrm{g} \cdot \mathrm{ml}^{-1} \mathrm{Chloramphenicol}$ The water samples and their $10^{-1}$ dilution were inoculated separately onto the agar media using the spread plate technique. Inoculated plates were incubated at ambient temperature $\left(28-31^{\circ} \mathrm{C}\right)$ for $48 \mathrm{~h}$. After incubation, colonies that developed on the agar plates were checked for their ability to fluoresce under ultra violet (UV) light. Isolated colonies that fluoresced under UV light were sub-cultured in a confluent streaking manner onto nutrient agar plates. Stock cultures of the isolates were developed from the confluent streak plates by scoping the colonial materials with the aid of sterile spatula and transferring into sterile $20 \%$ glycerol in sterile bijou bottles. Stock cultures were stored in the refrigerator at $4^{\circ} \mathrm{C}$. Colonies developed from the stock cultures were subjected to Gram staining, Methyl Red and Vogues-Proskauer test to confirm that the isolates belong to Pseudomonas species.

\subsection{Culture media preparation for biosurfactant production and optimization}

Glycerol-Mineral salts medium (Table 1a and Table 1b) were prepared for culturing the bacterium for biosurfactant production and optimization experiment. Thirteen different variations of the medium, with the thirteenth medium in triplicate, were prepared for the optimization experiment. The variations in the Glycerol-Mineral salts medium was based on three culture medium factors $(\mathrm{pH}, \mathrm{C}-\mathrm{N}$ ratio, C-P ratio), and on three levels $(-1,0,+1)$ for response surface analysis. The range of values of the selected culture medium factors and the chosen level of response surface analysis, based on the Box-Behnken design, is presented in Table 2. Based on the three selected factors with two extra centre points as required by the Response Surface Methodology, and with the aid of the Box-Behnken experimental design matrix (Table 3), a preparation of fifteen setups comprising thirteen different media with the thirteenth medium in triplicate were designed for the optimization experiment. In preparation of the thirteen variation of the GlycerolMineral salts medium with the thirteenth medium in triplicate, $100 \mathrm{ml}$ of the Glycerol-Mineral salts medium was dispensed into 15 conical flasks (250ml capacity) labeled 1-15, followed by the addition of the required amount of nitrate $\left(\mathrm{NaNO}_{3}\right)$ and phosphate $\left(\mathrm{KH}_{2} \mathrm{PO}_{4}\right)$ salts (Table 4). The calculations used in achieving the required amount of nitrate and phosphate can be found in Peekate and Abu (2017). The pH of the media was then adjusted accordingly (Table 3) using 1.0M NaOH and a pocket size pH meter (Hannah instrument, UK). The media were then sterilized in an Autoclave at $121^{\circ} \mathrm{C}$ for 15 minutes.

Table 1a Composition of the glycerol-mineral salts medium for culturing the bacterium for biosurfactant production

\begin{tabular}{lll}
\hline Constituent & Concentration & Quantity \\
\hline Glycerol (\% v/v) $_{\mathrm{KH}_{2} \mathrm{PO}_{4}}$ & 3 & $60 \mathrm{ml}$ \\
$\mathrm{MgSO}_{4} .7 \mathrm{H}_{2} \mathrm{O}(\mathrm{g} . \mathrm{L}-1)$ & $*$ & - \\
$\mathrm{NaCl}(\mathrm{g} . \mathrm{L}-1)$ & 0.4 & $0.8 \mathrm{~g}$ \\
$\mathrm{CaCl}_{2} .2 \mathrm{H}_{2} \mathrm{O}$ (g.L-1) & 1.0 & $2.0 \mathrm{~g}$ \\
$\mathrm{NaNO}_{3}$ & 0.1 & $0.2 \mathrm{~g}$ \\
$\mathrm{TES} \%$ v/v) & $*$ & - \\
Distilled water & 0.1 & $2 \mathrm{ml}$ \\
Total volume & - & $1938 \mathrm{ml}$ \\
\hline
\end{tabular}

TES: Trace elements solution; *the concentration was varied in order to achieve a particular C-N and C-P ratio. 
Table 1b Composition of TES

\begin{tabular}{ll}
\hline Constituent & g per L distilled water \\
\hline $\mathrm{MnSO}_{4} \cdot \mathrm{H}_{2} \mathrm{O}$ & 1.5 \\
$\mathrm{FeSO}_{4} .7 \mathrm{H}_{2} \mathrm{O}$ & 0.5 \\
$\mathrm{CuSO}_{4} .5 \mathrm{H}_{2} \mathrm{O}$ & 0.2 \\
$\mathrm{Na}_{2} \mathrm{MoO}_{4} \cdot 2 \mathrm{H}_{2} \mathrm{O}$ & 0.1 \\
$\mathrm{ZnSO}_{4} .7 \mathrm{H}_{2} \mathrm{O}$ & 1.5 \\
$\mathrm{H}_{3}$ & 0.3 \\
\hline
\end{tabular}

Table 2Culture medium factors and levels for response surface analysis

\begin{tabular}{llll}
\hline & \multicolumn{2}{c}{ Level } \\
Factor & $\mathbf{- 1}$ & $\mathbf{0}$ & $\mathbf{+ 1}$ \\
\hline $\mathrm{pH}$ & 5.5 & 7.0 & 8.5 \\
C-N ratio & 20 & 40 & 60 \\
C-P ratio & 10 & 13 & 16 \\
\hline C-N: carbon-nitrogen, C-P: carbon-phosphorus
\end{tabular}

Table 3 Combination of the culture medium factors for experimental runs using the Box-Behnken experimental design matrix

\begin{tabular}{llll}
\hline Run number & $\mathbf{. p H}\left(\mathbf{X}_{\mathbf{1}}\right)$ & $\mathbf{C - N}\left(\mathbf{X}_{2}\right)$ & $\mathbf{C - P}\left(\mathbf{X}_{3}\right)$ \\
\hline 1 & $-1(5.5)$ & $-1(20)$ & $0(13)$ \\
2 & $-1(5.5)$ & $+1(60)$ & $0(13)$ \\
3 & $+1(8.5)$ & $-1(20)$ & $0(13)$ \\
4 & $+1(8.5)$ & $+1(60)$ & $0(13)$ \\
5 & $-1(5.5)$ & $0(40)$ & $-1(10)$ \\
6 & $-1(5.5)$ & $0(40)$ & $+1(16)$ \\
7 & $+1(8.5)$ & $0(40)$ & $-1(10)$ \\
8 & $+1(8.5)$ & $0(40)$ & $+1(16)$ \\
9 & $0(7)$ & $-1(20)$ & $-1(10)$ \\
10 & $0(7)$ & $-1(20)$ & $+1(16)$ \\
11 & $0(7)$ & $+1(60)$ & $-1(10)$ \\
12 & $0(7)$ & $+1(60)$ & $+1(16)$ \\
13 & $0(7)$ & $0(40)$ & $0(13)$ \\
14 & $0(7)$ & $0(40)$ & $0(13)$ \\
15 & $0(7)$ & $0(40)$ & $0(13)$ \\
\hline Adapted from Zhang and Dequan $(2013)$, and Kumar $e t ~ a l . ~(2015)$. \\
\hline
\end{tabular}


Table 4 Amount of $\mathrm{NaNO}_{3}$ and $\mathrm{KH}_{2} \mathrm{PO}_{4}$ salts added to the Glycerol-Mineral salts media for each experimental run to achieve their respective $\mathrm{C}-\mathrm{N}$ and $\mathrm{C}-\mathrm{P}$ ratio.

\begin{tabular}{llllllll}
\hline $\mathbf{R} / \mathbf{N}$ & $\mathbf{C}$ & $\mathbf{N N}$ & $\mathbf{N}$ & $\mathbf{C}-\mathbf{N}$ & $\mathbf{K P}$ & $\mathbf{P}$ & $\mathbf{C}-\mathbf{P}$ \\
& $\mathbf{g} / \mathbf{1 0 0} \mathbf{~ m l}$ & $\mathbf{g} / \mathbf{1 0 0} \mathbf{~ m l}$ & $\mathbf{g} / \mathbf{1 0 0} \mathbf{~ m l}$ & $\mathbf{C} / \mathbf{N}$ & $\mathbf{g} / \mathbf{1 0 0} \mathbf{~ m l}$ & $\mathbf{g} / \mathbf{1 0 0} \mathbf{~ m l}$ & $\mathbf{C} / \mathbf{P}$ \\
\hline 1 & 1.47 & 0.45 & 0.0735 & 20 & 0.50 & 0.1131 & 13 \\
2 & 1.47 & 0.15 & 0.0245 & 60 & 0.50 & 0.1131 & 13 \\
3 & 1.47 & 0.45 & 0.0735 & 20 & 0.50 & 0.1131 & 13 \\
4 & 1.47 & 0.15 & 0.0245 & 60 & 0.50 & 0.1131 & 13 \\
5 & 1.47 & 0.22 & 0.0368 & 40 & 0.64 & 0.1470 & 10 \\
6 & 1.47 & 0.22 & 0.0368 & 40 & 0.40 & 0.0919 & 16 \\
7 & 1.47 & 0.22 & 0.0368 & 40 & 0.64 & 0.1470 & 10 \\
8 & 1.47 & 0.22 & 0.0368 & 40 & 0.40 & 0.0919 & 16 \\
9 & 1.47 & 0.45 & 0.0735 & 20 & 0.64 & 0.1470 & 10 \\
10 & 1.47 & 0.45 & 0.0735 & 20 & 0.40 & 0.0919 & 16 \\
11 & 1.47 & 0.15 & 0.0245 & 60 & 0.64 & 0.1470 & 10 \\
12 & 1.47 & 0.15 & 0.0245 & 60 & 0.40 & 0.0919 & 16 \\
13 & 1.47 & 0.22 & 0.0368 & 40 & 0.50 & 0.1131 & 13 \\
14 & 1.47 & 0.22 & 0.0368 & 40 & 0.50 & 0.1131 & 13 \\
15 & 1.47 & 0.22 & 0.0368 & 40 & 0.50 & 0.1131 & 13
\end{tabular}

$\mathrm{R} / \mathrm{N}$ : Run number, C: carbon concentration (the concentration of carbon in $100 \mathrm{ml}$ of medium containing $3 \% \mathrm{v} / \mathrm{v}$ glycerol is $1.47 \mathrm{~g} / \mathrm{L}$ ), $\mathrm{NN}^{\mathrm{N}} \mathrm{NaNO}{ }_{3}$ concentration, $\mathrm{N}$ : calculated nitrogen concentration, $\mathrm{KP}: \mathrm{KH}_{2} \mathrm{PO}_{4}$ concentration, $\mathrm{P}$ : calculated phosphorus concentration.

\subsection{Culturing for biosurfactant production and optimization}

A broth culture of a selected confirmed Pseudomonas species was first prepared by transferring $1 \mathrm{ml}$ of the stock culture into $200 \mathrm{ml}$ sterile nutrient broth (Titan Biotech Ltd., Rajasthan, India) which was then incubated at $37^{\circ} \mathrm{C}$ for $48 \mathrm{~h}$. After incubation, $1 \mathrm{ml}$ of the broth culture was inoculated into the fifteen sterile preparations of the Glycerol-Mineral salts medium. After inoculation, the setups were incubated at ambient temperature $\left(28-31^{\circ} \mathrm{C}\right)$ for four days on a PSU-20i Multi-functional Orbital Shaker (Keison Products, UK) operated at 150rpm for $8 \mathrm{~h}$ per working day. At the end of the incubation period, the foaming capacity of broth from the different setups was determined, and the different foaming capacities fitted using a generalized polynomial model (Eq. 1) for 3-factor design [4].

$Y=\beta_{0}+\beta_{1} X_{1}+\beta_{2} X_{2}+\beta_{3} X_{3}+\beta_{1,2} X_{1} X_{2}+\beta_{1,3} X_{1} X_{3}+\beta_{2,3} X_{2} X_{3}+\beta_{1,1} X_{1}^{2}+\beta_{2,2} X_{2}^{2}+\beta_{3,3} X_{3}^{2} \ldots$ (Eq. 1)

Where $\mathrm{Y}$ is the predicted foaming capacity; $\mathrm{X}_{1}, \mathrm{X}_{2}$, and $\mathrm{X}_{3}$ represent the values for the three factors $(\mathrm{pH}, \mathrm{C}-\mathrm{N}$ ratio, and C$P$ ratio); $\beta_{0}$ is the value of fitted response at the centre point of the design; $\beta_{1}, \beta_{2}$, and $\beta_{3}$ are the linear coefficients; $\beta_{1,2}$, $\beta_{1,3}$, and $\beta_{2,3}$ are the interaction coefficients; and $\beta_{1,1}, \beta_{2,2}$, and $\beta_{3,3}$ are the quadratic coefficients.

\subsection{Generating a prediction profile from the optimization experiment}

Model fitting was achieved using second order polynomial regression equations. The principles of Matrices was applied, with the aid of Microsoft excel@, in resolving the equations so as to obtain a prediction profile. The prediction profile was used to determine combinations of the values of $\mathrm{C}-\mathrm{N}$ ratio, $\mathrm{C}-\mathrm{P}$ ratio, and $\mathrm{pH}$ that will lead to high foaming capacity (indicating maximum biosurfactant production). The most favourable combination was used in a new experimental run for biosurfactant production.

\subsection{Culturing for biosurfactant production using optimized conditions}

About $500 \mathrm{ml}$ of a culture medium having the most favourable combination of $\mathrm{pH}, \mathrm{C}-\mathrm{N}$ ratio, and C-P ratio that will lead to the highest foaming capacity as determined from the prediction profile was prepared. The medium was sterilized in 
an Autoclave at $121^{\circ} \mathrm{C}$ for 15 minutes, allowed to cool, and inoculated with $5 \mathrm{ml}$ broth culture of the Pseudomonas sp. used in the optimization stage. On inoculation, the broth was incubated at ambient temperature $\left(28-31^{\circ} \mathrm{C}\right)$ for seven days on a PSU-20i Multi-functional Orbital Shaker (Keison Products, UK) operated at 150rpm for 8h per working day. At the end of the incubation period, the broth culture was screened for biosurfactant activity.

\subsection{Screening for biosurfactant activity}

\subsubsection{Surface tension measurements}

The capillary rise method was used in measuring the surface tension of the culture broth. A sterile capillary tube of about $0.2 \mathrm{~cm}$ diameter was used to measure the rise in height of the broth culture. The rise in height was then used to calculate the surface tension with the aid of Equation 2 [11].

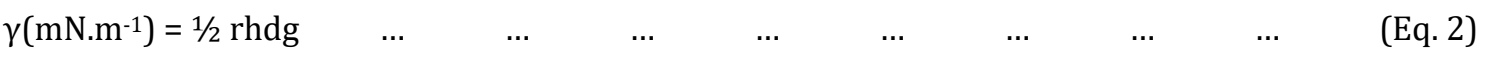

Where ' $r$ ' is the radius of the capillary tube in $\mathrm{cm}$; ' $h$ ' is the rise in height in $\mathrm{cm}$ of the liquid; ' $d$ ' is the broth density in g.cm ${ }^{-3}$; and ' $\mathrm{g}$ ' is the acceleration due to gravity in $\mathrm{cm} . \mathrm{s}^{-2}$, i.e. $980 \mathrm{~cm} . \mathrm{s}^{-2}$.

\subsubsection{Oil spread diameter}

About $40 \mathrm{ml}$ of distilled water was poured into Petri dishes and oil films generated on the water surface by adding several drops of diesel oil. A drop of broth culture was placed in the centre of the oil films, and the diameter of the ensuing zone of clearance measured.

\subsubsection{Drop collapse activity}

Each well in a ceramic plate was coated with a drop of used engine oil. The well plate was incubated at $37^{\circ} \mathrm{C}$ for about 1h. After incubation, two drops of the culture broth was transferred into the different oil-coated wells. After 1 minute, the shapes of the drops were observed with the aid of a magnifying lens.

\subsubsection{Foaming capacity}

The foaming capacity of the broth culture was determined by transferring $10 \mathrm{ml}$ of the broth into $50 \mathrm{ml}$ graduated measuring cylinders, which was then vortex vigorously for 1 minute. The foaming height and the total height was measured, and used to calculate the foaming capacity (FC). The calculation was done using equation 3 [13].

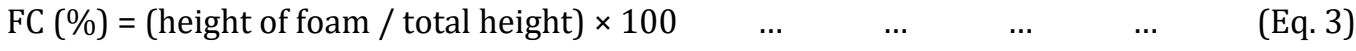

\section{Results and discussion}

\subsection{Identity of the fluorescent isolates}

Selected isolated colonies that fluoresced under UV light were coded P1 - P7. Results generated from Gram staining reaction, Methyl Red and Vogues Proskauer (MR-VP) tests carried out on the isolates is presented in Table 5. From the Table it can be seen that all the fluorescent isolates are Gram negative rods, and isolates P1 - P4, and P6 are MR-VP negative. Pseudomonas species are Gram negative rods and MR-VP negative [18, 19, 20]. Also, selected species of Pseudomonas are usually fluorescent [20], and may exhibit some level of antibiotic resistance. For instance, Pseudomonas aeruginosa has been cited to be intrinsically resistant to chloramphenicol [21]. It should be noted that the fluorescent bacteria were isolated using nutrient agar supplemented with $60 \mu \mathrm{g} . \mathrm{ml}^{-1}$ chloramphenicol. Bacterial isolates P1 - P4, and P6 are thus highly suspected to be species of Pseudomonas. 
Table 5 Identification test results of the fluorescent isolates

\begin{tabular}{clllll}
\hline ISC & GS & MPH & MR & VP & SO \\
\hline P1 & -ve & rods & -ve & -ve & Pseudomonas sp. \\
P2 & -ve & rods & -ve & -ve & Pseudomonas sp. \\
P3 & -ve & rods & -ve & -ve & Pseudomonas sp. \\
P4 & -ve & rods & -ve & -ve & Pseudomonas sp. \\
P5 & -ve & rods & -ve & +ve & Vibrio sp. \\
P6 & -ve & rods & -ve & -ve & Pseudomonas sp. \\
P7 & -ve & rods & -ve & +ve & Vibrio sp. \\
\hline
\end{tabular}

\subsection{Foaming capacity of broth from the experimental runs}

The foaming capacity of broth from the 15 experimental runs of the optimization experiment is presented in Table 6 . From the Table it can be seen that foaming was achieved in run-numbers 2-4, and 7-15. Foam formation has been achieved with biosurfactant at very low concentration [22]. In another related study, stable foam formation of 8 - 165 minutes with foaming height of $11-35 \mathrm{~mm}$ has been achieved with a species of Pseudomonas during biosurfactant production [23]. The various foaming capacities achieved in selected experimental runs in this study are thus indications of different level of biosurfactant production in the different experimental runs.

Fitting of the foaming capacities and the different combinations of the factors using a generalized polynomial model (Equation 1) is presented in Table 7 . In determining the coefficients $\left(\beta_{0}, \beta_{1}, \beta_{2}, \beta_{3}, \beta_{1,2}, \beta_{1,3}, \beta_{2,3}, \beta_{1,1}, \beta_{2,2}, \beta_{3,3}\right)$ in the polynomial model, the matrix equation $\hat{\beta}=\left(X^{T} X\right)^{-1} X^{T} Y$ [24] was used. From the calculations the coefficients $\beta_{0}, \beta_{1}, \beta_{2}$, $\beta_{3,} \beta_{1,2}, \beta_{1,3}, \beta_{2,3}, \beta_{1,1}, \beta_{2,2}, \beta_{3,3}$ were deduced to be - 513.03, 103.3804, 2.12108, 16.2848, - 0.1108, - 0.3656, - 0.0339, $6.1730,-0.0099$ and -0.4432 respectively. The polynomial model is thus written as,

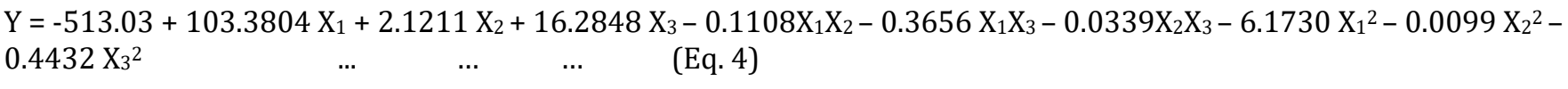

The analysis of variance of the polynomial model (Table 8) indicated that at least one of the coefficients is significant. In other words a regression model exists between foaming capacity and one or more of the factors (pH, C-N, and C-P).

Table 6 Foaming capacity and $\mathrm{pH}$ of broth from the 15 experimental runs

\begin{tabular}{llll}
\hline $\mathrm{R} / \mathrm{N}$ & $\mathrm{TH}(\mathrm{mm})$ & $\mathrm{FH}(\mathrm{mm})$ & $\mathrm{FC}(\%)$ \\
\hline 1 & 0 & 0 & 0 \\
2 & 20 & 2 & 10 \\
3 & 24 & 6 & 25 \\
4 & 23 & 5 & 21.7 \\
5 & 20 & 0 & 0 \\
6 & 20 & 0 & 0 \\
7 & 19 & 6 & 31.58 \\
8 & 16 & 4 & 25 \\
9 & 16 & 2 & 12.5 \\
10 & 20 & 6 & 30 \\
11 & 18 & 4 & 22.22 \\
12 & 19 & 6 & 31.58 \\
13 & 18 & 6 & 33.33 \\
14 & 17 & 5 & 29.41 \\
15 & 18 & 6 & 33.33 \\
\hline run number, TH: total height, FH: foaming hight, FC: foaming capacity
\end{tabular}


Table 7 Culture medium factors and foaming capacity values fitted into the generalized model

\begin{tabular}{lllllllllll}
\hline & $\mathbf{p H}$ & $\mathbf{C}-\mathbf{N}$ & $\mathbf{C}-\mathbf{P}$ & & & & & & & $\mathbf{F C}$ \\
& $\mathbf{X}_{\mathbf{1}}$ & $\mathbf{X}_{\mathbf{2}}$ & $\mathbf{X}_{\mathbf{3}}$ & $\mathbf{X}_{\mathbf{1}} \mathbf{X}_{\mathbf{2}}$ & $\mathbf{X}_{\mathbf{1}} \mathbf{X}_{\mathbf{3}}$ & $\mathbf{X}_{\mathbf{2}} \mathbf{X}_{\mathbf{3}}$ & $\boldsymbol{X}_{\mathbf{1}}^{2}$ & $\boldsymbol{X}_{\mathbf{2}}^{2}$ & $\boldsymbol{X}_{\mathbf{3}}^{2}$ & \\
{$[\mathbf{X}]$} & & & & & & & & & & $\mathbf{Y}$ \\
\hline 1 & 5.5 & 20 & 13 & 110 & 71.5 & 260 & 30.25 & 400 & 169 & 0 \\
1 & 5.5 & 60 & 13 & 330 & 71.5 & 780 & 30.25 & 3600 & 169 & 10 \\
1 & 8.5 & 20 & 13 & 170 & 110.5 & 260 & 72.25 & 400 & 169 & 25 \\
1 & 8.5 & 60 & 13 & 510 & 110.5 & 780 & 72.25 & 3600 & 169 & 21.7 \\
1 & 5.5 & 40 & 10 & 220 & 55 & 400 & 30.25 & 1600 & 100 & 0 \\
1 & 5.5 & 40 & 16 & 220 & 88 & 640 & 30.25 & 1600 & 256 & 0 \\
1 & 8.5 & 40 & 10 & 340 & 85 & 400 & 72.25 & 1600 & 100 & 31.58 \\
1 & 8.5 & 40 & 16 & 340 & 136 & 640 & 72.25 & 1600 & 256 & 25 \\
1 & 7 & 20 & 10 & 140 & 70 & 200 & 49 & 400 & 100 & 12.5 \\
1 & 7 & 20 & 16 & 140 & 112 & 320 & 49 & 400 & 256 & 30 \\
1 & 7 & 60 & 10 & 420 & 70 & 600 & 49 & 3600 & 100 & 22.22 \\
1 & 7 & 60 & 16 & 420 & 112 & 960 & 49 & 3600 & 256 & 31.58 \\
1 & 7 & 40 & 13 & 280 & 91 & 520 & 49 & 1600 & 169 & 33.33 \\
1 & 7 & 40 & 13 & 280 & 91 & 520 & 49 & 1600 & 169 & 29.41 \\
1 & 7 & 40 & 13 & 280 & 91 & 520 & 49 & 1600 & 169 & 33.33 \\
\hline & & & & FC: foaming capacity, [X]: design matrix. & & &
\end{tabular}

Table 8 Summary of the ANOVA of the generalized model

\begin{tabular}{|c|c|c|c|c|c|}
\hline $\begin{array}{l}\text { Source of } \\
\text { variation }\end{array}$ & $\begin{array}{l}\text { Degrees of } \\
\text { freedom }\end{array}$ & $\begin{array}{l}\text { Sum } \\
\text { squares }\end{array}$ & $\begin{array}{l}\text { Mean } \\
\text { squares }\end{array}$ & F statistics & $P$ value \\
\hline Regression & 3 & 2021.989 & 673.9962 & 36.69 & 0.1 \\
\hline Error & 11 & 202.0703 & 18.37 & & \\
\hline Total & 14 & 2224.0593 & & & \\
\hline
\end{tabular}

\subsection{Generated prediction profile from the optimization experiment}

Equation 4 was used in generating the prediction profiles (Table 9). The three dimensional (3-D) surface chart of the prediction profiles are presented in Figure 1a-1c. From Table 9 it is seen that the highest foaming capacity (32.04\%), indicating optimum biosurfactant production, is achievable at the combination of $\mathrm{pH} 7.0, \mathrm{C}-\mathrm{N}$ 40, and C-P 13. In Peekate and $\mathrm{Abu}$ [25], where surface tension was used as the response value, an optimized combination of $\mathrm{pH} 5.5$, C-N 20, and C-P 16 was achieved. The disparity between the two combinations could be attributed to a possible negative effect of acidic $\mathrm{pH}$ on foaming during biosurfactant production. Scrutinizing Table 6, it can be seen that the foaming capacity of run-numbers 1,5 , and 6 which are acidic experimental runs were $0 \%$. Also, observing the 3 -D surface chart of the prediction profiles it can be seen that at the acidic $\mathrm{pH}$, the foaming capacity for the various combinations were below $10 \%$ (Fig. 1a), whereas at neutral (pH 7.0) and alkaline $\mathrm{pH}$ (pH 8.5) foaming capacities were up to 30\% (Fig. 1b and 1c). It has been speculated that maximum foam volume depends on the $\mathrm{pH}$ of the production solution rather than the type of biosurfactant [26]. In other related studies, $\mathrm{pH}$ of 7.0, 7.8, and 8.0 has been shown to be an optimum factor for biosurfactant production [27, 28, 29]. The optimized combination of pH 7.0, C-N 40, and C-P 13 obtained in this study is thus a possible combination required for maximum biosurfactant yield. 
Table 9 Foaming capacity prediction profile for different combinations of $\mathrm{pH}, \mathrm{C}-\mathrm{N}$, and C-P.

\begin{tabular}{|c|c|c|c|c|c|}
\hline \multirow[t]{2}{*}{$\mathrm{X}_{2}(\mathrm{C}-\mathrm{N})$} & \multicolumn{5}{|c|}{$\mathrm{X}_{3}(\mathrm{C}-\mathrm{P})$} \\
\hline & 10 & 13 & 16 & 19 & 22 \\
\hline \multicolumn{6}{|l|}{ At pH 5.5} \\
\hline 20 & -13.26 & -3.05 & -0.82 & -6.57 & -20.29 \\
\hline 40 & -1.68 & 6.49 & 6.69 & -1.1 & -16.86 \\
\hline 60 & 1.97 & 8.11 & 6.27 & -3.54 & -21.34 \\
\hline 80 & -2.3 & 1.81 & -2.06 & -13.91 & -33.74 \\
\hline 100 & -14.48 & -12.41 & -18.32 & -32.2 & -54.06 \\
\hline \multicolumn{6}{|l|}{ At pH 7.0} \\
\hline 20 & 17.26 & 25.82 & 26.41 & 19.02 & 3.64 \\
\hline 40 & 25.51 & 32.04 & 30.59 & 21.16 & 3.76 \\
\hline 60 & 25.84 & 30.34 & 26.85 & 15.39 & -4.05 \\
\hline 80 & 18.25 & 20.71 & 15.19 & 1.7 & -19.77 \\
\hline 100 & 2.74 & 3.17 & -4.38 & -19.91 & -43.42 \\
\hline \multicolumn{6}{|l|}{ At pH 8.5} \\
\hline 20 & 20 & 26.92 & 25.86 & 16.82 & -0.2 \\
\hline 40 & 24.93 & 29.81 & 26.72 & 15.64 & -3.41 \\
\hline 60 & 21.93 & 24.78 & 19.65 & 6.55 & -14.54 \\
\hline 80 & 11.02 & 11.83 & 4.67 & -10.47 & -33.59 \\
\hline 100 & -7.81 & -9.03 & -18.23 & -35.4 & -60.56 \\
\hline
\end{tabular}

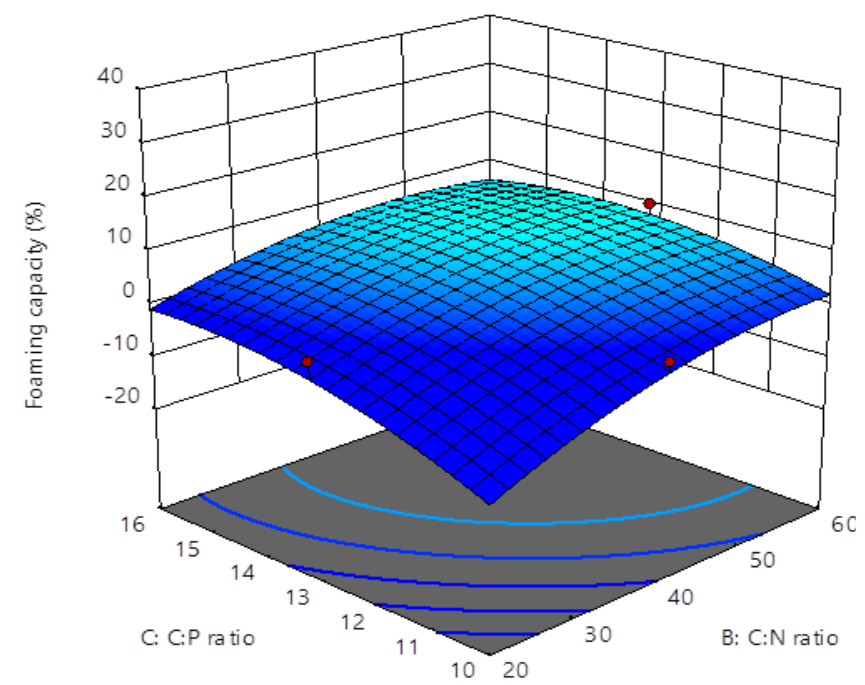

Figure 1a 3-D surface chart of the prediction profile for foaming capacity as a function of C-N and C-P ratio at pH 5.5. 


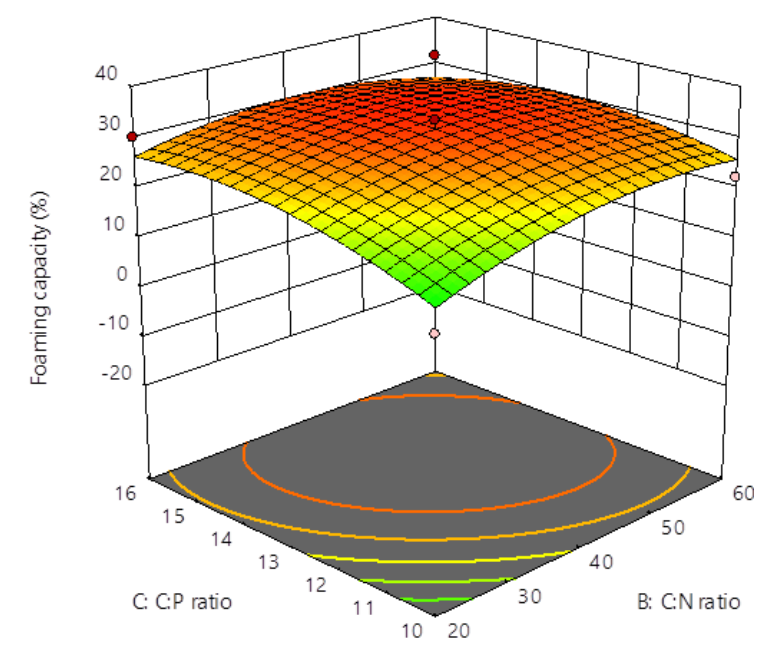

Figure 1b3-D surface chart of the prediction profile for foaming capacity as a function of C-N and C-P ratio at pH 7.0.

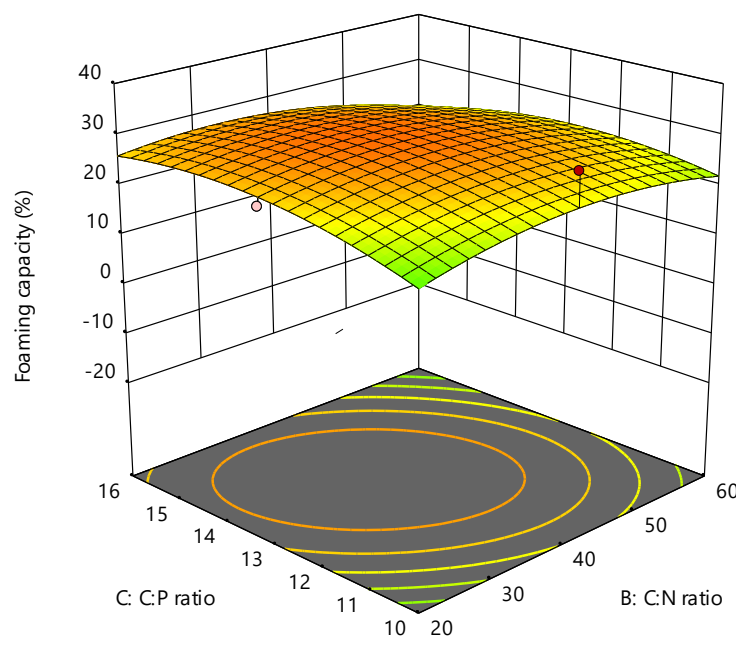

Figure 1c 3-D surface chart of the prediction profile for foaming capacity as a function of C-N and C-P ratio at pH 8.5 .

\subsection{Biosurfactant activity of broth from setup with optimized combination}

The biosurfactant activity of broth from setup with optimized combination (pH 7.0 / C-N 40 / C-P 13) is presented in Table 10. From the Table it can be seen that the drop collapse activity of broth from the setup was positive, and the surface tension was reduced from 56.43 to $35.28 \mathrm{mN} \cdot \mathrm{m}^{-1}$. Surface tension values that have been obtained for culture broth of biosurfactant producing microorganisms range from 26.7 to $38.75 \mathrm{mN}^{-1} \mathrm{~m}^{-1}$ [30, 31]. The considerable reduction of surface tension obtained in this study is thus an indication that biosurfactant was produced.

Table 10 Biosurfactant activity of broth from setup with optimized conditions

\begin{tabular}{lll}
\hline Activity & B7 & B0 \\
\hline Surface tension (mN.m-1) & 35.28 & 56.43 \\
Oil spread diameter (mm) & 5 & 0 \\
Drop collapse activity & + ve & - ve \\
\hline
\end{tabular}

B7: Setup having combination of pH 7.0, C-N 40, and C-P 13 after 7 days of incubation, B0: Setup on day 0 before inoculation. 


\section{Conclusion}

Foaming capacity, whose determination relies on readily available apparatus, was investigated in this study for use as response value during biosurfactant optimization through RSM. In using foaming capacity as the response value, optimized combination of pH 7.0, C-N 40, and C-P 13 was achieved where Pseudomonas sp. was used as the biosurfactant producing organism, and variants of a glycerol-mineral salts medium were used as the biosurfactant production medium. The optimized combination obtained in this study is a possible combination required for maximum biosurfactant yield as indicated by results obtained by other researchers. There is thus a possibility of using foaming capacity in place of surface tension as the response value during biosurfactant optimization through RSM. The strength of this possibility can be evaluated in future research works where foaming capacity will be used to re-assessed combinations obtained through the use of surface tension.

\section{Compliance with ethical standards}

\section{Disclosure of conflict of interest}

The authors declare that there are no conflicts of interest.

\section{References}

[1] Cameotra SS, Makkar RS, Kaur J and Mehta SK. (2010). Synthesis of biosurfactants and their advantages to microorganisms and mankind. In: Sen R (Ed.), Biosurfactants. Springer Science and Business Media, New York, 261-280.

[2] Banat IM, Satpute SK, Cameotra SS, Patil R and Nyayanit NV. (2014). Cost effective technologies and renewable substrates for biosurfactant production. Frontiers in Microbiology, 5, 1-18.

[3] Zhang X and Dequan L. (2013). Response surface analyses of rhamnolipid production by Pseudomonas aeruginosa strain with two response values. African Journal of Microbiological Research, 7(22), 2757-2763.

[4] Kumar AP, Janardhan A, Radha S, Viswanath B and Narasimha G. (2015). Statistical approach to optimize production of biosurfactant by Pseudomonas aeruginosa 2297. 3 Biotech, 5, 71-79.

[5] Tuleva BK, Ivanov GR and Christova NE. (2002). Biosurfactant production by a new Pseudomonas putida strain. Z. Naturforsch, 57c, 356-360.

[6] Benincasa M, Marques A, Pinazo A and Manresa A. (2010). Rhamnolipid surfactants: alternative substrate, new strategies. In: Sen R (Ed.), Biosurfactants. Springer Science and Business Media, New York, 170-184.

[7] Chandankere R, Yao J, Masakorala K, Jain AK and Kumar R. (2014). Enhanced production and characterization of biosurfactant produced by a newly isolated Bacillus amyloliquefaciens USTBb using response surface methodology. International Journal of Current Microbiology and Applied Sciences, 3(2), 66-80.

[8] Bento FM, Camargo FAO, Okeke BC and Frankenberger Jr. WT. (2005). Diversity of biosurfactant producing microorganisms isolated from soils contaminated with diesel oil. Microbiological Research, 160, 249-255.

[9] Mahdy HM, Fareid MA and Hamdan MN. (2012). Production of biosurfactant from certain Candida strains under special conditions. Researcher, 4(7), 39-55.

[10] Walter V, Syldatk C and Hausmann R. (2010). Screening concepts for the isolation of biosurfactant producing microorganisms. In: Sen R (Ed.), Biosurfactants, Springer Science and Business Media, New York, 1-13.

[11] Negi AS and Anand SC. (1985). A Textbook of Physical Chemistry. New Age International, New Delhi, India, 8889.

[12] Almansoory AF, Idris M, Abdullah SRS and Anuar N. (2014). Screening for potential biosurfactant producing bacteria from hydrocarbon-degrading isolates. Advances in Environmental Biology, 8(3), 639-647.

[13] El-Sheshtawy HS and Doheim MM. (2014). Selection of Pseudomonas aeruginosa for biosurfactant production and studies of its antimicrobial activity. Egyptian Journal of Petroleum, 23, 1-6.

[14] Satpute SK, Banpurkar AG, Dhakephalkar PK, Banat IM and Chopade BA. (2010). Methods for investigating biosurfactants and bioemulsifiers: a review. Critical Reviews in Biotechnology, 30(2), 127-144. 
[15] Chandran P and Das N. (2011). Characterization of sphorolipid biosurfactant produced by yeast grown on diesel oil. International Journal of Science and Nature, 2(1), 63-71.

[16] Dhail S and Jasuja ND. (2012). Isolation of biosurfactant-producing marine bacteria. African Journal of Environmental Science and Technology, 6(6), 263-266.

[17] Pacheco GJ, Ciapina EMP, Gomes EB and Nei PJ. (2010). Biosurfactant production by Rhodococcus erythropolis and its application to oil removal. Brazilian Journal of Microbiology, 41, 685-693.

[18] Prescott LM, Harley JP and Klein DA. (1999). Microbiology, fourth edition. The McGraw-Hill companies, Inc., New York, 243.

[19] Reynolds MT, Falkiner FR, Hardy R and Keane CT. (1979). Differentiation of fluorescent Pseudomonas by their effect on milk agar. Journal of Medical Microbiology, 12, 379-382.

[20] Stanier RY, Adelberg EA and Ingraham JL. (1977). General Microbiology, fourth edition. The Macmillan press Ltd., London, 593-595.

[21] Morita Y, Tomida J and Kawamura Y. (2014). Responses of Pseudomonas aeruginosa to antimicrobials. Frontiers in Microbiology, 4, 1-8.

[22] Razafindralambo H, Paquot M, Baniel A, Popineau Y, Hbid C, Jacques P and Thonart P. (1996). Foaming properties of surfactin, a lipopeptide biosurfactant from Bacillus subtilis. Journal of the American Oil Chemists' Society, 73, 149-151.

[23] Dehghan-Noudeh G, Moshafi MH, Behravan E, Torkzadeh S and Afzadi MA. (2009). Screening Three Strains of Pseudomonas aeruginosa: Prediction of Biosurfactant-Producer Strain. American Journal of Applied Sciences, 6, 1453-1457.

[24] Draper NR and Smith H. (1998). Applied Regression Analysis, third edition. Hoboken, NJ: John Wiley and Sons, Inc., 115-134.

[25] Peekate PL and Abu GO. (2017). Optimizing C: N ratio, C: P ratio and pH for biosurfactant production by Pseudomonas fluorescens. Journal of Advances in Microbiology, 7(2), 1-14.

[26] Ozdemir G, Peker-Basara S and Helvaci SS. (2004). Effect of pH on the surface and interfacial behavior of rhamnolipids R1 and R2. Colloids and Surfaces A: Physicochemical and Engineering Aspects, 234, 135-143.

[27] Deepika KV, Kalam S, Sridhar PR, Podile AR and Bramhachari PV. (2015). Optimization of rhamnolipid biosurfactant production by mangrove sediment bacterium Pseudomonas aeruginosa KVD-HR42 using Response Surface Methodology. Biocatalysis and Agricultural Biotechnology, 5, 38-47.

[28] Effiong E, Agwa OK and Abu GO. (2019). Optimization of Biosurfactant production by a novel Rhizobacterial Pseudomonas species. World Scientific News, 137, 18-30.

[29] Persson A, Osterberg E and Dostalek M. (1988). Biosurfactant production by Pseudomonas fluorescens 378: growth and product characteristics. Applied Microbiology and Biotechnology, 29, 1-4.

[30] Thavasi R, Sharma S and Jayalakshmi S. (2011). Evaluation of screening methods for the isolation of biosurfactant producing marine bacteria. Journal of Petroleum and Environmental Biotechnology, S1.001, 1-6.

[31] Viramontes-Ramos S, Portillo-Ruiz MC, Ballinas-Casarrubias ML, Torres-Munoz JV, Rivera-Chavira BE and Nevarez-Moorillon GV. (2010). Selection of biosurfactant/bioemulsifier-producing bacteria from hydrocarboncontaminated soil. Brazilian Journal of Microbiology, 41, 668-675. 